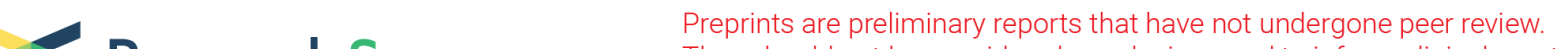 $\begin{array}{ll}\text { Research Square } & \text { They should not be considered conclusive, used to inform clinical practice, } \\ \text { or referenced by the media as validated information. }\end{array}$
}

\section{Current Challenges Lack of the legality of Nurse Prescribing in Intensive Care Units: A Qualitative Study}

\section{Azam Naderi}

PhD Student, Student Research Committee, School of Nursing and Midwifery, Shahid Beheshti University of Medical Sciences, Tehran

\section{Abbas Abbaszadeh}

PhD, Professor, School of Nursing and Midwifery, Shahid Beheshti University of Medical Sciences,

\section{Tehran}

\section{Rostam Jalali}

PhD, Associate Professor, School of Nursing and Midwifery, Kermanshah University of Medical

Sciences, Kermanshah

\section{Marzieh Pazokian ( $D$ Pazokian@sbmu.ac.ir)}

PhD, Assistance Professor, Department of Medical-Surgical Nursing, Shahid Beheshti University of Medical Sciences, Tehran

\section{Camelia Rohani}

PhD, Associate Professor, Department of Community Health Nursing, School of Nursing and Midwifery, Shahid Beheshti University of Medical Sciences, Tehran

\section{Research Article}

Keywords: Nurse prescribing, Medication, Intensive Care Unit, Qualitative Study, Nurse

Posted Date: October 8th, 2021

DOl: https://doi.org/10.21203/rs.3.rs-951979/v1

License: (c) (1) This work is licensed under a Creative Commons Attribution 4.0 International License. Read Full License 


\section{Abstract \\ Background}

Nurse prescribing is a successful innovation in the role of nurses in the world. It is crucial to assess the challenges of nurse prescribing roles in the Intensive Care Units (ICU), due to the needs of the patients in these units. This qualitative study aimed was to explore the experts' experiences regarding lack of the legality of nurse prescribing in ICU in the healthcare system of Iran.

\section{Methods}

Data were collected through semi structured face-to-face interviews with 33 experts chosen according to purposive and snowballing sampling with maximum variation. The interviews were analysed using Graneheim and Lundman's conventional content analysis method. After overviewing the interviews, semantic units, codes, subcategories, categories and themes were extracted. The qualitative data were analysed using MAXQDA software version 10.

\section{Results}

The main theme of the study was "The current challenges due to the illegality of nurse prescribing" with five categories and 12 subcategories. The five categories included the "current reality of illegal prescribing", "patient safety threat", "current conflicts", "physician as an autocratic group," and "prescribing demands."

\section{Conclusion}

Despite the nurse prescribing role has been legalized and implemented in many countries, there is still no law in the ICU and other places in Iran, and this lack of legality has led to the conflicts and challenges for the patients, nurses and healthcare system. The legality of nurse prescribing in the ICU can prevent medication errors and endangering patient safety.

\section{Introduction}

Evidence shows that in the health care system of countries, it is necessary to develop the prescribing role for nurses to improve health care services demand (1). Medicine prescribing has long been limited to the medical profession (2), though in the past 50 years, nurses all over the world have been officially or unofficially involved in medicine prescription all over the world (3). Nurse prescribing first emerged in 1969 in the Idaho State in the United States. It has gone through a long gradual process of development and implemented in many countries, including the United States, Canada, New Zealand, Australia, England, and Ireland (4). It is being implemented in a growing number of countries $(5,6)$. A specific group 
of nurses is allowed to prescribe Medications in Europe, And moreover of these changes occurred in the past two decades (7).

In countries such as the United States and Canada, nurses have long been involved in advanced performance programs as specialists nurse or nurse practitioners that right to prescribe medication is part of them (8). Lack of physicians, requiring patients to more accessible to medications, developing the roles of nurse practitioners (9), better use of professional and scientific skills of nurses and saving time and treatment costs for patients (10) are the causes of the legality of nurse prescribing. Nurse prescribing by nurse practitioners in the ICU was first proposed in 1990 in the United States, followed by England, Canada, Australia and New Zeeland. Evidence shows that there are different reasons for nurse prescribing in the ICU. Due to the clinical needs of critically ill patients in these units, the role of these nurses was specially developed to prescribe in the ICU (11). Based on the type of Medications used in these units, the role of the ICU nurses is essential and critical (12). Moreover, many high-risk Medications are being used in these units, which may cause complications if misused (13).

An estimation shows that the critically ill patients in the ICU receive twice as much medication as patients in other wards (14). Based on a review article on 20,000 prescribed medications by physicians in ICU of the United Kingdom, in $15 \%$ of cases, one or more medication errors occurred (15). One-fifth of medication errors are life-threatening in the ICU (15-18). ICU nurses routinely prepare and use medications and are aware of the complexity of medications prescriptions in the ICU. The development of nurse prescribing will improve the patients safety of caring services (1). Also, nurses may play an essential role in reducing medication errors; they are responsible for safe medication use for patients, and having theoretical knowledge and quality regarding the medications is crucial for them (19).

Contrary to Iran, where nurse prescribing is intangible and illegal, nurse prescribing is implemented in a growing number of countries $(20,21)$. Since medicine prescription in the ICU is critical and it, should be limited to experienced nurses with advanced skills (22). Based on the legal nursing duties, nurses are not allowed to prescribe Medications. It has been reported in a qualitative study in Iran, despite not being legal and contrary to popular belief in the healthcare system of Iran, nurse prescribing occurs unofficially in most hospital wards, especially in the emergency wards and ICU. Nurses will be prosecuted in the case of any complication though patients and their need for safe and effective healthcare services are at the core of this development. Thus, it is vital to develop the role of nurse prescribing in the countries where it is not allowed (22). Some challenges are barrier and prevent nurse prescribing, Therefore it is crucial to identify these challenges and their consequences to help nurses to apply their scientific and technical potential abilities (23). Thus, this qualitative Study is intended to explore the expert's experiences regarding nurse prescribing in the ICU at the healthcare system of Iran and the current challenges of it's the illegality.

\section{Background}


Iran is a vast country with a population of around 70 million (24). In 1916, the first nursing school in Iran was established in Tabriz, and by 1935 it was the only nursing school in Iran. The government then established four new nursing schools in the big cities of Mashhad, Shiraz, Rasht and Tehran. In the healthcare system of Iran, the legislation of the Clinical Competency License for Nurses was passed on the 26th of April 2016 (25). According to this legislation, all graduate nurses need to have a Clinical Competency License for their clinical work. The License is valid for five years (26). Currently, there are bachelor, master and doctoral nursing programs in Iran. For the bachelor program, nursing education lasts for four years, which is the basic nursing program at the university level (27).

The prescription of medications by nurses is not legal in the healthcare system of Iran, and there is still no particular protocol or guideline for it. However, there are several studies in this field for future planning. The present study is ongoing research in this field. Evidence shows that in the healthcare system of Iran, nurse prescribing is unofficially performed by the ICU nurses due to the different reasons, such as emergencies situations, sometimes not on time access to the doctors and saving patients' life and safety (22). Therefore, it is essential to produce national standards for prescribing medications by the ICU nurses in the healthcare system of Iran (28).

\section{Methods}

\section{Study design}

This is a qualitative descriptive Study and is part of a mixed-method study with a Sequential exploratory approach.

\section{Participants}

Thirty-three participants were chosen with purposive and snowballing sampling in this study. This study inclusion criterion included a minimum of three years of working experience in ICU for nurses, physicians, pharmacologists and faculty members. A strategic selection was used regarding age, gender, work experience and ICU experience.

\section{Data Collection}

Data was collected through 34 semi-structured interviews with participants and a 90-minute interview group with four of them. One participant being interviewed twice. The data collection continued until data was saturation. Participants were selected from five hospitals affiliated with two medical universities, two Schools of Nursing and Midwifery, the experts of the Health Ministry, Board of Nursing, Nursing Organization and Intensive Care Association. The participants included 11 ICU nurses, five physicians with intensive care fellowship, two clinical pharmacologists at ICU, seven faculty members at the university, eight nursing managers at the hospital, nursing faculty, the experts of the Health Ministry, Nursing Organization., To have access to abundant information, a focus group was held with four experts of the nursing deputy of the Health Ministry. 
The interview was started with a general question regarding nurse prescribing. Some examples of the questions are, "What is your experience for prescription of medication for your patient at ICU? ", "What challenges have been associated with the illegality of nurse prescribing in the ICU?", "How necessary do you consider the legality of nurse prescribing in the ICU in the current situation of the health care system?", "Please, tell me your experiences in this regard.". Some exploratory and clarifying questions were asked during the interview for a better and deep understanding. After permission from participants, all interviews were recorded by the voice recorder device. The interviews' time ranged from 25 to 108 minutes. MAXQDA 10 software was used for the writing the interviews and analysis of the information.

\section{Data Analysis}

The interviews were analysed using Graneheim and Lundman's (2004) conventional content analysis method (29). After each interview, the recorded voice was listened accurately and typed verbatim in a word file. All files were checked with the recorded voices by the first author. Then, the first author read the interview several times to get the main idea by drowning in the data. Each interview was considered a unit for analysis. Subsequently, the semantic units were identified and the initial codes were generated. Next, the similar initial codes were summarized in one code. The codes were classified into the subcategories, which formed the main categories and the theme of the Study. The research team members discussed data analysis in three meetings.

Following the approval of the Ethics Committee of the university, the researcher referred to the nursing offices of affiliated hospitals of the university to receive and code the list of ICU nurses. Next, using a random numbers table, the sample size was set proportional to each hospital's number. Then, the researcher referred to these nurses based on their work plan and explained the study objectives, if they were willing to participate in the study, provided them with a questionnaire. When a nurse was not willing to participate in this study, the nurse was replaced by another nurse on the name list preceding or following the concerned nurse.

\section{The Rigor of the Study}

Lincoln and Guba criteria (2005) were used to strengthen the data, including credibility, dependability, confirmability, and transferability (30). For data credibility, the first author was drowned in the data collection and analysis for ten months from April 2019 to February 2020. The research team members checked individually randomly ten interviews and their analyses. Also, they evaluated all data analysis procedures and discussed the codes, subcategories, and categories in three meetings. For data dependability, extracted codes, subcategories, categories and themes were evaluated and confirmed by three participants, and three referees with a doctoral degree in nursing who were experts with qualitative studies.

To assess data confirmability, all study steps were described so that others may understand it. Also, participants were chosen with the highest diversity (in terms of age, gender, job, educational level, and work place and work experiences). To reassure data transferability, he interviews were written immediately verbatim, and their statements were accurately and richly described with objective 
experiences and purposing examples and quotations of the participants. The study method was described in detail to be used for future researches.

\section{Ethical considerations}

This Study approved with IR.SBMU.PHARMACY.REC.1398.023 ethical code in the ethics research committee of Shahid Beheshti University of Medical Sciences. Before starting the Study, the first author met the participants in a short meeting and explained about the Study and its aims, and then got oral and written consent for participating in the Study and being interviewed. They were informed that participation in the Study is voluntary, and all their information will be confidential. Semi-structured interviews were conducted individually with each participant at the preferred time and place for the participants.

\section{Results}

The mean age of participants in this Study was $47.15 \pm 10.68$ years. Also, the mean working experience in nursing and mean working experience in ICU were respectively $21.61 \pm 10.81$ and $11.30 \pm 7.53$ years. The mean length of interviews was $57.39 \pm 20.36$ minutes. The characteristics of the participants are presented in Table 1.

Table 1

Participants characteristics ( $n=33$ ).

\begin{tabular}{|c|c|c|c|c|c|c|}
\hline $\begin{array}{l}\text { Participants } \\
\text { Variables }\end{array}$ & & $\begin{array}{l}\text { Nurse } \\
(n=11)\end{array}$ & $\begin{array}{l}\text { Manager and } \\
\text { politician health } \\
(n=10)\end{array}$ & $\begin{array}{l}\text { Faculty } \\
\text { member } \\
(n=5)\end{array}$ & $\begin{array}{l}\text { Physician } \\
(n=5)\end{array}$ & $\begin{array}{l}\text { Clinical } \\
\text { pharmacist } \\
(n=2)\end{array}$ \\
\hline \multirow[t]{2}{*}{ Gender } & Male & 5 & 2 & 1 & - & 1 \\
\hline & Female & 6 & 8 & 4 & 5 & 1 \\
\hline \multirow{4}{*}{$\begin{array}{l}\text { Educational } \\
\text { level }\end{array}$} & Bachelor & 8 & - & - & - & - \\
\hline & Master & - & 5 & 3 & - & - \\
\hline & Ph.D. & 3 & 5 & 2 & - & 2 \\
\hline & Fellowship & - & - & - & 5 & - \\
\hline
\end{tabular}

The main theme of the study was " The current challenges due to the illegality of nurse prescribing", and included five categories: The current reality of illegal prescribing, Patient safety threat, Current conflicts, Physician as an autocratic group, and Prescribing demands (Table 2). 
Table 2

Subcategories, categories and theme of the study.

\begin{tabular}{|c|c|c|}
\hline Theme & Category & Subcategory \\
\hline \multirow{12}{*}{$\begin{array}{l}\text { The current challenges due } \\
\text { to the illegality of nurse } \\
\text { prescribing }\end{array}$} & \multirow{3}{*}{$\begin{array}{l}\text { The fact of illegal } \\
\text { prescription of } \\
\text { medication }\end{array}$} & - Secret medication prescription (white lie) \\
\hline & & - Agreed prescription \\
\hline & & - Prescription in critical situations \\
\hline & \multirow[t]{3}{*}{ Patient safety threat } & - Improper prescription of some physicians \\
\hline & & $\begin{array}{l}\text { - Wrong prescription by some physicians and } \\
\text { nurses' ignorance }\end{array}$ \\
\hline & & $\begin{array}{l}\text { - Interaction between prescribed medications } \\
\text { by different physicians }\end{array}$ \\
\hline & \multirow[t]{3}{*}{ Current conflicts } & - Knowledge-performance conflict \\
\hline & & - Monitoring-performance conflict \\
\hline & & - Conflict in Justice \\
\hline & \multirow{2}{*}{$\begin{array}{l}\text { Physicians as an } \\
\text { autocratic group }\end{array}$} & - Physician dominance \\
\hline & & $\begin{array}{l}\text { - Performing many physician duties by ICU } \\
\text { nurse and recording the procedures for } \\
\text { physicians }\end{array}$ \\
\hline & Prescribing demand & $\begin{array}{l}\text { - Mental concern and nursing prescribing } \\
\text { demand }\end{array}$ \\
\hline
\end{tabular}

\section{The Current Reality Of Illegal Prescribing}

This category includes three subcategories of "secret prescription or white lie", "Agreed prescription" and "prescription in the critical situations".

Most participants stated the nurse prescribing in ICU occurring illegally and unofficially, weather with physician agreement or in the emergent cases to save patients' life, or is a hidden manner without being recorded or reported. It includes replacing medicine with another medicine, not administering the medicine, or changing the dose. Here are three quotes in this line:

\section{Agreed prescription}

"The prescription law requires revised. What the law says is different from what is happening in reality! Especially it is required more in ICU since the patient's condition is unstable; we are not available all the time, so I let the nurses whom I trust." (P16, Fellowship Physician) 


\section{Secret prescription}

An ICU head nurse, stated on the hidden prescription, "We are doing it in a hidden manner if it is manifest, I am morally responsible for patients! If physicians persuade me I am doing wrong, I accept. Otherwise, I do what I know is true when they leave and tell them lies! Because patient is important for me ..." (P3) Prescribing by nurses in the critical situations

"When the patient's urgent needs arise, should we decide what to do? Until the decision to take emergency action is left to the doctor, the patient is lost! And this is the reason for the illegal action of the nurses!" (P28, Nurse Manager)

\section{Patient Safety Threat}

This category includes "Improper prescription of some physician", "Wrong prescription of some physicians and nurse ignorance" and "Interaction between prescriptions by different physicians".

Improper visit and prescription of physician

ICU head nurse, stated on the high quantity and low quality of some visits: "Unfortunately, physician routine practice is to visit more cases and get more fee! It is one of our current problems." (P5, Head Nurse)

Improper prescription of some physician is attributed to the short duration of visits and not paying attention to previous and objective symptoms and not wholly knowing patients for proper prescription. This leads to a gap in nurse to physician information transfer, which may threaten the patient's safety.

Participant 7, a nurse with 13 working experience in ICU, stated: "in ICU, physicians spend half an hour for visits which leads to improper prescription, but nurses are in contact with patients for 24 hours."

"It is a reality that information transmission has always been associated with gaps! It is obvious! ICU nurses are continuously at the patient bed, but physicians are not! Physicians can not touch and see many things in patients and should listen to nurse reports. This may cause a wrong decision." (P20, Fellowship Physician)

\section{A wrong prescription of some physicians and nurse ignorance}

Sometimes, nurses are aware of the wrong prescription of physicians, though they ignore it and do the prescription, since the physical may not treat well.

"Sometimes you get very upset when you see a mistake and physician's order is wrong, but you are not allowed to give any opinion, you get upset since patient suffers." (P13, Clinical Pharmacist) 


\section{Interaction between medications prescribed by different physicians}

Admitting physicians, residing physicians, and consultants. ICU admitted that patients are being visited by some physicians due to their various complications. Multiple medications may lead to improper administration and different interactions, as well as excess costs for patients.

"A patient in ICU, had his/her specialist physician, anaesthesiologist! They consulted for some patient issues, then they ordered three series of orders and medications, many of which interacted with each other, and none of them checked the medicine interactions and effects." (P19, Faculty of Member)

\section{Current Conflicts}

It included "knowledge-performance conflict", "monitoring-performance conflict", and "Conflict in Justice".

\section{Knowledge-Performance Conflict}

In Iran, nurses are not allowed to prescribe medications, yet they are directly responsible for critically ill and complicated patients whose general condition may deteriorate and require immediate intervention, which is a conflict. A member of a nursing organization with 28 years of experience in ICU, stated:

"If we think that our nurses do not have enough knowledge, we should not face patient with the risk of death, if not, why don't we provide these conditions legally?" (P24)

\section{Monitoring-Performance Conflict}

Nurses are not allowed to prescribe medications despite long-term direct care and continuous patient monitoring with advanced devices, though physicians are allowed to prescribe despite minimal monitoring of patients and medicine effects.

"I, as an ICU nurse, have all devices for patient monitoring! In fact, I have strong monitoring, but my performance and authority are poor! While physicians have performance without monitoring and take their information from nurse's reports." (P17, Nurse)

\section{Conflict in Justice}

This conflict occurs in regard to the injustice of people in receiving health care services in terms of the duality of the prescribers. This duality is regarding the prescribing allowance for health workers in rural health care centers contrary to nurses and not trusting them even for prescribing the simplest medications in the urban health care centres.

"Are people of a society divided into first hand and second hand? If nurse medicine prescribing is bad? Why are health workers in rural areas allowed without any relevant background? While BS nurses with a good scientific basis are not allowed to prescribe even a tablet." (P21, Policymaker) 
Medicine prescribing by peer groups such as midwives and lower groups such as rural health workers were examples of justice conflict. The followings are two quotes from academic and clinical managers in nursing; respectively:

"... how can health workers prescribe medications, a midwife can prescribe a medicine for her patients, tough an MS or Ph.D. nurse is not allowed." (P14, Manager in nursing faculty)

"Now, a health worker without a university degree, even undergraduate, just passing a short-term course can prescribe over 80 medications. Thus a nurse who studied four years for BS and three years for MS is not allowed." (P28, Clinical Manager)

\section{Physicians as an autocratic group}

It includes "physician dominance" and "performing many physician duties by the nurse and recording the procedures for physicians". Nurse participants stated that physicians often do not disagree with the nurse prescribing to lessen their workload, and even sometimes order in a coercive voice some of their therapeutic duties to the nurses.

\section{Physician dominance}

"... In paternalistic structure of the health system, there is an authoritarian parent called doctors who have not allowed anyone to make any decisions! Moreover, their discourse on nursing has been the child's obedient discourse, which, if not bit submissive, will certainly be dealt with." (P21, Policymaker in nursing)

\section{Performing many physician duties by the nurse and recording the procedures for physicians}

"On many times; we do all the works for patients and make them stable, then the physician comes and orders what we have done and finally, he is thanked." (P24, Nurse)

Prescription demand

It includes: "Mental concern and nursing prescribing demand due to their ability".

This category included postgraduate nurse's complaints against the lack of authority, constant regret about the lack of legal authority despite their ability, demand for prescribing at least to the extent of meeting patients' vital needs. A nurse with 20 years of working experience, stated:

"I should say that it is one of the main concerns of all nurses. Many times patients required a medicine; we knew what to do, though we could not because we were not legally allowed!" (P5, Nurse)

\section{Discussion}


This study explored the experiences of experts about nurse prescribing in the ICU at the healthcare system of Iran and the challenges of the illegality of medications' prescription by the ICU nurses. "Current conflicts on the illegality of nurse prescribing" in the ICU was extracted as the main theme of the study with 13 subcategories.

According to the results of this study, the illegality of nurse prescribing in the ICU has led to an important conflict in the current situation. "The current state of illegal prescribing" was controversial, especially in emergencies and lack of access to a physician. Illegal prescriptions are being implemented in various forms in the intensive care unit. It is either in emergencies situations to save the patient's life, which is registered by nurses, and they accept the consequences, or it is based on the agreement and trust between physicians and skilled nurses in which physicians unofficially let nurses prescribe. Also, it may occur in conditions of physician lack of cooperation and concern about the patient's condition based on their knowledge and experience, when nurses prescribe secretly and don't record it anywhere due to fear of the legal consequences.

In a study, most nurses were willing to the development of the prescribing role of nurses since they considered it as formalization and announcement of a role which is being informally played for years (31-33). Illegal prescribing is neither a new issue, nor it is limited to Iran, as Bowskill stated in his study that nurses prescribed medications for their patients long before they get a legal license, and obtaining the legal authority, was the next step in a natural course (34). According to Gerard's Study in 2015, even in countries where nurse prescribing is illegal, nurses have to prescribe medications in emergencies situations and in intensive care units to save the lives of patients, and they diagnosis disease alongside physicians in emergency cases (17). The results of this part of our Study confirm the results of the only qualitative Study in this field in Iran, which showed that nurse prescribing is done informally in most wards, especially in the emergency wards and intensive care units, while medicine prescribing is ICU is sensitive and should be limited to experienced advanced nurses (22).

Therefore, patient safety is at the potential risk of wrong prescribing. In addition to illegal prescriptions, improper prescriptions by some physicians in the ICU were one of the factors that threatened patient safety. The majority of participants stated that the short duration of physician visits based on patient instant examination and nurse reports lead to the physician's lack of proper knowledge of the patient's situation and gaps in the information transfer from nurses to physicians leading to wrong decisions which endanger patient safety. In contrast, the constant supervision of nurses leads to the full knowledge and monitoring of the effects of therapeutic interventions by nurses. Given that there are a high number of high-risk medications in this section, improper treatment can lead to injury to patients (13).

In a Study, most errors in the ICU were caused due to the inability, insufficient knowledge, an incorrect understanding of the critical information received from patients (7). Another study showed that most medicine errors in the ICU occurred during the prescription (35). Some participants pointed out that the improper prescribing of some physicians and the ignorance of some nurses endangers the patient's safety. In some cases, nurses administer the medications despite being aware of the improper 
prescription for fear of the physician's inappropriate reaction. A study in the United States indicated that medical errors were the third leading cause of death in the United States. Medication errors often occur due to incorrect prescriptions of physicians (36).

While nurses play an important role in reducing medication errors and are responsible for the safe use of these medications for patients (19) and reviewing medications and their dosage of medications are essential examples of patient safety measures by nurses (37). On the other hand, strengthening and maintaining an effectiveness relationship between physicians and nurses, especially in the intensive care unit, is essential for the optimal treatment of patients. Nurses play an important role in the decisionmaking process of prescribing medications by physicians and monitoring the prescribed medications to reduce medication errors and support physicians in prescribing or eliminating certain medications $(2,5)$. According to participants, ICU patients are often visited and consulted by different physicians, leading to the prescription of multiple medications by different physicians. Medication prescribing for critically ill ICU patients is twice as much as other hospitalized patients (38). Most of these prescriptions are without monitoring the effects, interactions, and side effects, resulting in an increased incidence of medicine errors, which endangers patients' safety (33).

Monitoring the effect of prescribed medications is a crucial task often done by nurses, since nurses are responsible for the special care of critically ill patients (39), while the interactions of health care providers and their participation are essential to maintaining patient safety and they should be aware of the medication interactions (40). The most crucial skill of ICU nurses is the rapid evaluation of patient response to medications and predicting their physical and mental responses (12).

Participants also complained about the current conflicts, including monitoring-performance conflict. In their opinion, ICU nurses are responsible for the continuous care, control, and monitoring of critically ill patients and need sufficient specialized knowledge and skills to manage them. Even physician prescribing is based on nurse's reports. Though their performance is not proportionate, and they are not allowed to prescribe even the most apparent medications, such as painkillers and antipyretics, and they have to wait for physicians. Other articles insisted on the body of knowledge, skills, and experience for nurses in the intensive care unit to provide effective care to patients and their families and create a healing environment (41). Since these patients require complicated evaluations, vigorous treatment, and continuous monitoring (12), on the other hand, considering that the main policy of the Iranian health system is public equality and justice, the majority of the participants considered the illegality of prescribing nursing as a contradiction injustice.

Since nurses are not licensed to prescribe medications despite their ability, experience, and academic background, while midwives or health workers in rural health centers are licensed to prescribe a specific list of medications, which they believe it had positive effects on the health system. "Why don not we trust nurses with academic education while health workers in rural areas are trusted?" On the other hand, the duality of the people towards the prescribing person was discussed. In the current situation, the prescription by the nurses in the hospital centers is not trusted, but the health of people in the rural and 
marginal areas has been risked by licensing less qualified health workers. This has led to another constant mental challenge regarding the illegality of medication prescribing by skilled nurses, which was told by the majority of participants in various categories of nursing with regret. In this regard, nurses believed that due to their knowledge and experience, they can to diagnose and treat patients under care, and they will be qualified after receiving a brief education, though they are not given this opportunity at the moment, and they rely on physician order for the most apparent prescriptions, according to studying the previous experiences of ICU nurses and their familiarity with the complexities of prescribing in ICU which potentially prepare and empower them for proper medicine prescription (42) and it is among the factors leading to the success of nursing prescription, promotion of educational programs, and improve their professional and clinical competencies. Having a nursing concern is a factor in developing this role. Findings suggest that one of the obstacles to the development of this role is related to the nurses themselves and their misconceptions and lack of interest in this category. Postgraduate courses, such as nurse prescribing in the MS course of ICU nursing or adult and paediatric emergency nursing, will provide the opportunity that nurses be allowed to prescribe medications in their specialized field (23).

On the other hand, participants pointed to the dominance of physicians, which is mainly due to their topdown view. Many physicians prescribing duties are performed by nurses informally in the ICU and registered as physician practice who receives moral and material interests, leads to a lack of appreciation of the efforts of nurses and thus their frustration. In the legality of nurse prescribing, the opposition of physicians has always been a significant, obstacle. Physicians have believed since a long time ago that they are at the forefront of the health care system and must protect their prestige (43) since this is the boundary between physicians and nurses (44). Arian et al. study in 2018 showed that the hierarchical norms and top-down view of physicians led to their critical view and not supporting and their dissatisfaction with nurse prescribing (23).

\section{Limitations}

Our study has some limitations that should be considered. The study took place in ICU, so there are limitations for generalizing our findings to other clinical wards. Thus, it is recommended that further studies be conducted in other settings.

Furthermore, although in this study we tried to select participants with maximum diversity in age, sex, profession, level of education, place of work and work experience, but did not have the opportunity to interview with health insurance managers and the organization of the medical system. In other studies, it is it is recommended that interview these groups individually or in groups.

\section{Impact Statement}

The lack of legality of nurse prescribing in the ICU in the health care system of Iran has led to the current conflicts and challenges. The legality of it, can prevent many medical errors and endangering patient safety, and also protect ICU nurses from the consequences of illegal prescriptions. Assessment of these 
challenges, releasing protocols and guidelines as well as leading the healthcare system towards legalizing of nurse prescribing in the ICU, will reduce patient safety threats and improve the quality of caring services by ICU nurses.

\section{Conclusion}

Nurse prescribing is legal and implemented in many countries in the world, but have not yet been legalized in Iran. Participants' experiences showed that there are unofficial and illegal nurse prescribing in the ICU. Therefore, it is vital this issue to be evaluated in the ICU, where nurse prescribing frequently occur illegally, especially in emergencies and lack of access to a physician. Most of the participants stated that one of the challenges of illegality prescribing nursing in ICU is threatening the safety of patients. Since the ICU nurses are responsible for the continuous care, control, and monitoring of critically ill patients and due to their knowledge and experience, they can to diagnose and treat patients under care, and they will be qualified after receiving a brief Theoretical and clinical training.

\section{Declarations}

\section{Ethics approval and consent to participate}

This Study approved with IR.SBMU.PHARMACY.REC.1398.023 ethical code in the ethics research committee of Shahid Beheshti University of Medical Sciences. The written informed consent was obtained from all the participants. All the experiment protocol for involving humans was in accordance to guidelines of national/international/institutional or Declaration of Helsinki.

\section{Consent to publish}

No Applicable

\section{Availability of data and material}

The identified datasets analyzed during the current study are available from the corresponding author on reasonable request.

\section{Competing interests}

The authors declare there are no competing interests

\section{Funding}

The authors used no funding sources to declare.

\section{Authors' contributions}


All authors (AN, AA, RJ, MP and CR) planned and designed the study. AN was the leading author for drafting of the article and responsible for identifying relevant references. All authors contributed to data analysis and they were in close collaboration for critical revisions of the manuscript. All authors read and approved the final manuscript.

\section{Acknowledgments}

This study is part of the Doctoral Thesis of the first author (AN), which was approved by the Research Ethics Committee of the Shahid Beheshti University of Medical Sciences (SBMU) and supported by the School of Nursing and Midwifery of SBMU. We would like to thank all participants who accepted to be interviewed in this study.

\section{References}

1. Banning M. Nurse prescribing, nurse education and related research in the United Kingdom: a review of the literature. Nurse Educ Today. 2004;24(6):420-7.

2. Carey N, Stenner K, Courtenay M. An exploration of how nurse prescribing is being used for patients with respiratory conditions across the east of England. BMC Health Services Research. 2014;14(1):27.

3. Courtenay M. Nurse prescribing, policy, practice and evidence base. $\mathrm{Br} \mathrm{J}$ Community Nurs. 2008;13(12):563-6.

4. NICE. (National Institute for Health and Care Excellence). Non-medical prescribing. Accessed 20/8/2019 https://bnfniceorguk/guidance/non-medical-prescribing 2019.

5. Badnapurkar A, Bressington D, Jones M, Nelson D, Thomas D, Mehndi M, et al. Perception of nurse prescribing among nurses and psychiatrists in a developing country: A cross-sectional survey. International Journal of Mental Health Nursing. 2017;27(2):866-76.

6. Murphy $M$, While A. Medication administration practices among children's nurses: a survey. British journal of nursing. 2012;21(15):928-33.

7. Kroezen M, Francke AL, Groenewegen PP, van Dijk L. Nurse prescribing of medicines in Western European and Anglo-Saxon countries: a survey on forces, conditions and jurisdictional control. International journal of nursing studies. 2012;49(8):1002-12.

8. NPC. (National Prescribing Centre). Training non-medical prescribers in practice - A guide to help doctors prepare for and carry out the role of designated medical practitioner.. http://www2uweacuk/services/Marketing/what-canistudy/Professionaldevelopment/Designated_medical_practitioners_guidepdf. 2005.

9. Oguisso T, Freitas GFd. Enfermeiros prescrevendo medicamentos: possibilidades e perspectivas. Revista Brasileira de Enfermagem. 2007;60(2):141-4.

10. Plonczynski D, Oldenburg N, Buck $M$. The past, present and future of nurse prescribing in the United States. Nurse Prescribing. 2003;1(4):170-4. 
11. DoH. (Department of Health). Nurse and pharmacist prescribing powers extended. London: Department of Health. 2005.

12. Ling DL, Lyu CM, Liu H, Xiao X, Yu HJ. The necessity and possibility of implementation of nurse prescribing in China: An international perspective. International Journal of Nursing Sciences. 2018;5(1):72-80.

13. Maier CB. Nurse prescribing of medicines in 13 European countries. Human Resources for Health. 2019;17(1):95.

14. Cope LC, Abuzour AS, Tully MP. Nonmedical prescribing: where are we now? Therapeutic advances in drug safety. 2016;7(4):165-72.

15. Buckley P, Grime, J., Blenkinsopp. Inter- and intra-professional perspectives on non-medical prescribing in an NHS trust. Pharmaceutical Journal 2006;277(7420):394-8.

16. Fisher R. Nurse prescribing: a vehicle for improved collaboration, or a stumbling block to interprofessional working? Int J Nurs Pract. 2010;16(6):579-85.

17. Horton R. Nurse-prescribing in the UK: right but also wrong. Lancet. 2002;359(9321):1875-6.

18. RCN. (Royal College of Nursing). RCN fact sheet: Nurse prescribing in the UK. December 2014. April 2012 (updated December 2014) international@rcnorguk. 2014.

19. Shannon E, Spence W. The attitudes and views of GPs and physicians to prescribing by heart failure nurse specialists. British Journal of Cardiac Nursing. 2011;6(9):450-5.

20. Jiao S, Murimi IB, Stafford RS, Mojtabai R, Alexander GC. Quality of Prescribing by Physicians, Nurse Practitioners, and Physician Assistants in the United States. Pharmacotherapy. 2018;38(4):417-27.

21. Darvishpour A, Joolaee S, Cheraghi MA, Mokhtari-Lakeh N. Iran's health policymakers' views on barriers and facilitators of nurse prescribing in their context: A qualitative study. Iran J Nurs Midwifery Res. 2016;21(3):297-305.

22. Courtenay M, Carey N, Burke J. Independent extended and supplementary nurse prescribing practice in the UK: a national questionnaire survey. Int J Nurs Stud. 2007;44(7):1093-101.

23. Kroezen M, van Dijk L, Groenewegen PP, de Rond M, de Veer AJ, Francke AL. Neutral to positive views on the consequences of nurse prescribing: Results of a national survey among registered nurses, nurse specialists and physicians. Int J Nurs Stud. 2014;51(4):539-48.

24. Stenner K, Carey N, Courtenay M. Implementing nurse prescribing: a case study in diabetes. J Adv Nurs. 2010;66(3):522-31.

25. Furlong EaRS. Advanced nursing practice: policy, education and role development. Journal of Clinical Nursing. 2005;14(9):1059-66.

26. Fletcher CE, Copeland LA, Lowery JC, Reeves PJ. Nurse Practitioners as Primary Care Providers Within the VA. Military Medicine. 2011;176(7):791-7.

27. Camp J. Public policy implementation of nurse prescribing. Nurse Prescribing. 2008;6(6):252-7.

28. Lockwood EB, Fealy GM. Nurse prescribing as an aspect of future role expansion: the views of Irish clinical nurse specialists. J Nurs Manag. 2008;16(7):813-20. 
29. Clancy M. Irish Emergency Nurses' Attitudes towards Role Expansion in, and Barriers to, Nurse Prescribing. Masters dissertation, Dublin: Royal College of Surgeons in Ireland. 2011.

30. DoH. (Department of Health). Quality Critical Care: Beyond 'Comprehensive Critical Care': A Report by the Critical Care Stakeholder F orum. London: DoH. 2005

31. DoH. (Department of Health). Improving Patients' Access to Medicines: A Guide to Implementing Nurse and Pharmacist Independent Prescribing within the NHS in England. London: Department of Health. 2006.

32. Zarzeka A, Panczyk M, Belowska J, Mazur N, Paz B, Gotlib J. Nurse prescribing: Attitudes of medical doctors towards expanding professional competencies of nurses and midwives. Journal of the Pakistan Medical Association. 2019;69:1199-204.

33. Zarzeka A, Panczyk M, Zmuda-Trzebiatowska H, Belowska J, Samoliński L, Iwanow L, et al. Nurse prescribing. Knowledge and attitudes of polish nurses in the eve of extending their professional competences: Cross-sectional study. Acta Poloniae Pharmaceutica - Drug Research. 2017;74(3):1031-8.

34. Arian M NM, Raiesdana N, Oghazian MB. Identifying the fields of activity, challenges andpositiveoutcomesof nursing prescription:Asystematic review. Hayat, Journal of School of Nursing and Midwifery,Tehran University of Medical Sciences. 2018;24(3):279-95. (Persian).

35. Amanda LE, Rebecca J. Nurse prescribers' experiences of prescribing. Journal of Clinical Nursing. 2004;13(7):796-805.

36. Wilson DM, Murphy J, Nam MA, Fahy A, Tella S. Nurse and midwifery prescribing in Ireland: A scopeof-practice development for worldwide consideration. Nursing \& Health Sciences. 2018;20(2):26470.

37. Jabareen HM. Skill mix development in general practice: a mixed method study of practice nurses and general practitioners.PhD thesis, University of Glasgow. 2009.

38. Connor R, McHugh Á. The experience of the non-medical prescriber in the emergency department in Ireland. Journal of Prescribing Practice. 2019;1(5):240-5.

39. UKCCNMHV. (United Kingdom Central Council for Nursing, Midwifery and Health Visiting). The future of professional practice, the Council's standards for education and practice following registration. London: Springer. 1994.

40. Bray K, Wren I, Baldwin A, St Ledger U, Gibson V, Goodman S, et al. Standards for nurse staffing in critical care units determined by: The British Association of Critical Care Nurses, The Critical Care Networks National Nurse Leads, Royal College of Nursing Critical Care and In-flight Forum. Nursing in Critical Care. 2010;15(3):109-11.

41. Fairley D. Discovering the nature of advanced nursing practice in high dependency care: a critical care nurse consultant's experience. Intensive and Critical Care Nursing. 2005;21(3):140-8.

42. Kroezen $M$, de Veer $A$, Francke $A$, Groenewegen $P$, van Dijk L. Changes in nurses' views and practices concerning nurse prescribing between 2006 and 2012: results from two national surveys. J Adv Nurs. 2014;70(11):2550-61. 
43. Weglicki RS, Reynolds J, Rivers PH. Continuing professional development needs of nursing and allied health professionals with responsibility for prescribing. Nurse education today. 2015;35(1):227-31.

44. Carberry M, Connelly S, Murphy J. A prospective audit of a nurse independent prescribing within critical care. Nurs Crit Care. 2013;18(3):135-41.

45. Gerard K, Tinelli M, Latter S, Smith A, Blenkinsopp A. Patients' valuation of the prescribing nurse in primary care: a discrete choice experiment. Health Expectations. 2015;18(6):2223-35. 